\title{
BARTH EN DIE KINDERDOOP
}

Prof. L. Floor.

\section{'n Klip in die bos}

Karl Barth, wie se honderdste geboortedag hierdie jaar herdenk word, was in velerlei opsigte 'n provokerende teoloog. Hy het nie altyd teologiese paaie bewandel wat reeds lank uitgetrap was nie maar hy het telkens gesoek na nuwe weë. Daar sit dan ook iets uitdagends in sy hele teologie.

Sy beroemde Römerbrief (1919) waarin Barth die transendensie van God so sterk beklemtoon as 'n krisis van al wat menslik is in religie, moraal en kultuur, het die teologiese wêreld soos 'n tydbom getref.

Sy stryd met Emil Brunner, sy konflik met Friedrich Gogarten en sy kontrovers met Rudolf Bultmann is almal bewyse dat Barth ' $n$ eie pad wou loop en op 'n eie wyse wou kom tot 'n vertolking van die Evangelie. Sy ernorme werkkrag, sy humor en ook sy geloof het spreekwoordelik geword. Die nuwere teologie soos beoefen byvoorbeeld deur Dorothé Sölle, het Barth nie aangespreek nie. Hy noem hulle "Plattfusstheologen" ('n Baselse dialek vir papband). Hulle het 'n gebrek aan pneuma, hulle hou nie rekening met die Heilige Gees nie en daarom lyk hulle so droefgeestig. Hulle maak of hulle self die hele wêreld moet dra (Dekker, $1969: 147$ ).

Die aand voor sy afsterwe het Barth nog 'n lang telefoongesprek gevoer met sy vriend Eduard Thurneysen. Hulle praat oor die donker situasie in die wêreld. In sy laaste woorde klink Barth se geloof kragtig deur. Hy roep sy ou vriend, wat sy lewe lank by hom gestaan het, toe: "Nur die Ohren nicht hängen lassen! Gott sitzt im Regimente". (Thurneysen in 'n brief aan dr. G. Puchinger, d.d. 3 Febr. 1969).

Karl Barth het die moed gehad om teen die teologiese stroom van sy tyd in te gaan. Ook selfs teen 'n eeue-oue tradisie van die kerk.

So het Karl Barth ook gekom met 'n geheel eie siening op die doop. Terwyl die Tweede Wêreldoorlog in al sy heftigheid gewoed het, het Barth met sy bestryding van die kinderdoop gekom. Op 7 Mei 1943 lewer hy in Gwatt aan die Thunersee voor 'n groep Switserse teologiese studente 'n voordrag oor die doop onder die titel: Die Kirchliche Lehre von der Taufe. Hy noem die kinderdoop nie 'n egte doop nie maar 'n verduisterde doop. Dit bly merkwaardig dat Barth tog van oordeel is dat die doop van suigelinge, soos hy dit noem, wanneer dit eenmaal plaasgevind het, nie herhaal moet of mag word nie. Hulle doop is volgens Barth wel uiters bedenklik maar dit beteken nog nie dat daardie doop op 'n ongeldige wyse voltrek is nie (Barth, $1943: 28-29,48$ ).

In 1967 wanneer Barth reeds 81 jaar oud is, skrywe hy van sy Kirchliche Dogmatiek die vierde deel oor die leer van die versoening. Barth het sien aankom dat hy sy Dogmatiek nie tot voltooiing kan bring nie. Die gedeelte waar hy die doop bespreek het hy egter ge- 
reed gehad en daarom het hy sy doopleer in hierdie deel opgeneem. Hy noem dit "Das christliche Leben" (Fragment) met as ondertitel "Die Taufe als Begründung des christlichen Lebens".

Voor die verskyning van K.D., IV, 4 in 1967 was daar nog volgelinge van Barth wat gemeen het dat hulle meester op sy verwerping van die kinderdoop sou terugkom, want wanneer ons Barth se beide geskrifte oor die doop met mekaar vergelyk dan moet dit ons tref dat Barth in sy eerste geskrif nog die sakramentele karakter van die doop erken en dit laat die moontlikheid vir 'n erkenning van die kinderdoop nog oop. Dit is God wat in die doop handel.

Maar in sy laaste geskrif oor die doop verwerp hy duidelik die sakramentele karakter van die doop en behandel hy geheel konsekwent, omdat volgens hom die doop 'n daad van die mens is, die doop as deel van die etiek.

Sy laaste geskrif oor die doop was seker net soos sy eerste referaat oor dieselfde onderwerp ' $n$ klip in die bos.

In die "Vorwort" van sy laaste geskrif oor die doop vermeld hy dat hy baie geleer het uit die studie van sy seun Markus Barth, Die Taufe ein Sakrament (1951). Hy kla daaroor dat die eksegete en dogmatici nie soveel aandag aan die boek van sy seun gegee het nie maar "nicht so der greise Vater des Verfassers" (KD., IV, S,X).

\section{Barth's argumente teen die kinderdoop}

In sy laaste geskrif oor die doop trek Barth skerp skeiding tussen die doop met die Heilige Gees en die doop met water. In die Gereformeerde dogmatiek is daar altyd onderskeid gemaak tussen die Christologie wat te doen het met die verwerwing van God se heil en die Pneumatologie wat verband hou met die toepassing van God se heil. Die Heilige Gees pas dit wat Christus verwerf het aan die mens toe in die weg van die gebruik van die heilsmiddels: Woord en sakrament. Barth stel die vraag: hoe word Christus se heilswerk "zum Ereignis", tot 'n werklike gebeure vir die mens. Sy antwoord is: deur die Heilige Gees.

In hierdie verband spreek Barth dan oor die doop met die Heilige Gees. Hy noem die doop met die Gees 'n "Reinigung und also Neubestimmung eines Menschen durch die Mitteilung und das Werk des Heiligen Geistes" (1967:33). Barth dui die Geestesdoop met verskillende sterk uitdrukkings aan wanneer hy praat van 'n "effektives, kausatives, ja kreatives u. zw. göttlich wirksames, göttlich verursachendes göttlich schöpferisches Handeln an und im Menschen" (1967:37). Barth se pragtige uiteensetting van die doop met die Heilige Gees vertoon sterk ooreenkoms met wat die Gereformeerde dogmatiek die wedergeboorte noem.

Hier gee Barth ons 'n sterk wapen teen almal wat onderskeid maak tussen wedergeboorte as 'n eerste weldaad van die Heilige Gees en die Geestesdoop as 'n "second blessing" (vgl. Floor, 1982: 110-116; Jonker, 1981:215). Die waterdoop is nou volgens Barth die menslike antwoord op God se handele in die Geestesdoop. Die waterdoop "setzt diese (die Geestesdoop, Fl.) voraus" (1967: 45). Barth sê van die waterdoop: "Die Taufe... ist nicht Gnadenträger, 
nicht Gnadenmittel, nicht Instrument der Gnade. Die Taufe antwortet auf das eine 'Mysterium', das eine 'Sakrament', der Geschichte Jesu, seiner Auferstehung, der Ausgiessung des Heiligen Geistes: sie selbst ist kein Mysterium, kein Sakrament" (1967:112).

Hier gaan Barth oor die Rubikon. Hy neem standpunt in teenoor die ekumeniese tradisie van die Christelike kerk. Daar was nog altyd 'n konsensus tussen die Gereformeerde, die Rooms-Katolieke en die Lutherse opvatting oor die doop: die doop is 'n 'Mysterium', 'n sakrament. Wie volgens Barth die doop as 'n sakrament beskou, as 'n handeling van God, "doketisiert" die doop (1967:112) en soos in sy Christologie is ook Barth in sy doopsleer doodsbang vir dosetisme. Dosetisme vergoddelik wat slegs menslik is. Daarom is die doop volgens Barth uitsluitlik die menslike antwoord op die doop met die Heilige Gees.

'n Kind kan nog nie op die Geestesdoop antwoord nic. In 'n vraaggesprek oor die doop het Karl Barth die bekende uitspraak gelewer: 'n Doopbediening sonder 'n belydende dopeling is ewe onmoontlik as 'n teregstelling sonder slagoffer (Berkouwer, $1947: 20$ ).

\section{Die Skrifbewys}

Barth het self besef dat wanneer iemand die sakramentelc karakter van die doop afwys en die doop nie as 'n handeling wil sien waarin God werksaam is nie, maar alleen as 'n menslike handeling dan is die Skrifbewys van fundamentele belang.

Om sy standpunt Skriftuurlik te staaf, voer Barth die volgende Skrifbewyse aan: die oproep van Ananias tot Paulus om hom te laat doop (Hand 22:16), die reiniging van die hart van 'n slegte gewete (Hebr $10: 22$ ) en die was van die liggaam met rein water (Ef $5: 22$ e.v.). Hoewel Barth heelwat meer tekste in hierdie verband bespreek, kom ons met die drie tekste hierbo genoem by die kern van Barth se besware teen die sakramentele karakter van die doop.

Dit is onmoontlik om in die kort verband van hierdie artikcl Barth se eksegese op die voet te volg. Bowendien het prof. Adrio König Barth se eksegese in besonderhede nagegaan en sorgvuldig getoets. Hy het oortuigend aangetoon dat die drie tekste saam met ander soos byvoorbeeld Hand $2: 38 ; 1$ Kor $6: 11$ en Tit $3: 5$ op unieke wyse aantoon waarom die apostels spanningsloos oor die heilsgebeure in Christus as die eintlike grond en fondament van ons saligheid kon skryf en oor die doop as die teenwoordigstelling (representasie) van hierdie heil (König, 1971:51). Ook P. J. Versteeg, wat alle tekste oor die doop deeglik geëksegetiseer het, het tot die konklusie gekom dat die doop in die Nuwe Testament betrokke is op die heilswerk van Christus. "De doop stelt in relatie met het heilsgebeuren in Christus. De doop heeft voortdurend het heilswerk van Christus als veronderstelling" (Versteeg, $1983: 116$ ).

König wys daarop dat die verhouding kruis - doop of die direkte verband tussen doop en sondevergifnis, dit vir ons onmoontlik mak om die sakramentele karakter van die doop te ontken (König, 1971:47-50). Dit is God wat in die doop handel. Tereg vra König: as Barth kruis en doop as God's werk en menslike antwoord teenoor 
mekaar plaas, waarom dan nie kruis en verkondiging nie? (König, 1971:50).

Nou erken Barth self dat die verskillende dooptekste in die Nuwe Testament wel sakramenteel verstaan kan word, maar hy voeg daarby dat hulle nie sakramenteel verstaan moet word nie (vgl. Bremmer, 1983:501). Die doop is vir Barth uitsluitlik 'n menslike daad, ' $n$ "Absage" in die betekenis van boete en skuldbelydenis en "Zusage" in die sin van geloofsbelydenis. Die doop is nie as sakrament ' $n$ instrument vir die Heilige Gees wat ons geloof versterk deur God se beloftes in ons harte te verseël en te bevestig nie.

König kom op deeglike eksegetiese gronde tot die konklusie dat die doop in die Nuwe Testament meer is as die mens se antwoord op God se handele in Christus. In en deur die doop handel God, want in die Nuwe Testament funksioneer die doop in direkte samehang met en betrokkenheid op die kruisdood van Christus en sonder om die kruis as die enigste heilskousaliteit te bedreig. Daarom moet die sakramentele karakter van die doop gehandhaaf word (König, 1971: $51-54)$. En wanneer aangetoon is dat dit God is wat in die doop handel, dan is dit weer moontlik om te vra na die regmatigheid van die kinderdoop.

\section{Kerkhistoriese argumente}

In sy beredenering waarom die kinderdoop verwerp moet word, wys Karl Barth ook op die kerkgeskiedenis. Hy is van oordeel dat in die tradisie van die kerk die kinderdoop onlosmaaklik verbind is met die eenheid van kerk, staat en samelewing wat sedert die tyd van Konstantyn die Grote ontstaan het.

Hierdie eenheid het in die Middeleeue uitgegroei tot die sogenaamde corpus Christianum. Van hierdie ineenvlegting van kerk, staat en samelewing is volgens Barth die kinderdoop die teken.

Die doop moes die eenheid in stand hou en alleen al die gedagte dat die eenheid tussen kerk, staat en samelewing kon wegval, was volgens Barth "das Argument aller Argumente" om die kinderdoop te handhaaf (Barth, $1967: 185$ ).

Alhoewel die kinderdoop volgens Barth waarskynlik reeds vroeg in die geskiedenis van die kerk voorgekom het, sclfs in dic apostoliese tyd, het dit volgens Barth tog eers algemene praktyk geword in die tyd toe die kerk onder keiser Konstantyn een met die volk geword het. Die kerk wou toe aan hierdie volkskarakter en ryksom. vang vashou en daarom is na die algemene praktyk van die kinder doop gegryp om sodoende die Christendom teen ondergang te beskerm (Barth, $1967: 185$ ).

Dit kan nie ontken word dat iemand wat in 'n Christelike huis, in 'n gekerstende samelewing opgroei en in die Christelike kerk opgeneem is, so gewoond kan raak aan die doop dat hy die betekenis en inhoud daarvan nie tot sy eie maak nie. Die oplossing is egter nie om dan maar die kinderdoop te verwerp nie, maar om so iemand juis sy doop te leer verstaan. 


\section{Dogmatiese besware}

Barth se skerpste kritiek op die kinderdoop is sy bestryding van die sakramentsleer van die Reformatore en dan met name Calvyn. Die eerste leer van die kinderdoop is deur die Reformatore opgestel. Dit was bedoel as 'n apologeties-polemiese verweer teen die Anabaptiste.

Maar Barth beskou die leer van die kinderdoop soos deur die Reformatore uitgespel as 'n "Fremdkörper", 'n "novum", 'n "alienum" in hulle teologie (Barth, $1967: 183,187$ ).

Volgens Barth vertoon Calvyn se sakramentsleer 'n innerlike teenstrydigheid veral waar Calvyn sy doopsbeskouing in sy meer voldrae vorm in die Institusie van 1559 (IV. 14, 1) uiteensit en Calvyn stel dat die doop nie slegs God se beloftes aan ons verseël nie, maar dat die doop ook 'n wederkerige betuiging van ons vroomheid jeens Hom is (mutuale nostrae erga imsum pietatis testificatio). Hierdie tweede element val by Calvyn se verdediging van die kinderdoop geheel weg, so betoog Barth. Calvyn laat dit "sang- und klang. los" val (Barth, $1967: 192$ ).

Calvyn beroep hom slegs op die samehang tussen doop en besnydenis (IV, 16) en dit is volgens Barth net ' $n$ 'Appendix', 'n aanhangsel by Calvyn se doopleer en nie ' $n$ integrerende deel daarvan nie.

Calvyn het die grond vir die kinderdoop veral gesoek in die eenheid van Ou en Nuwe verbond. Waar bly by Calvyn die differentia, die verskil tussen die twee verbonde wat Calvyn in II, 11 van sy Institusie so treffend uiteengesit het, so roep Barth uit. Kan Kerk en Israel op een niveau geplaas word? Die Christelike kerk "kon stituiert sich nicht durch die Folge der Generationen". Hy rekruteer nie lidmate "durch Zeugungen und Geburten" nie (Barth, 1967: $196)$.

Aan die einde van sy bestryding van die kinderdoop stel Barth nog eenmaal die hele probleem skerp wanneer hy wys op die verhouding doop - geloof by die kinderdoop, die relasie tussen "Taufgeschehen auf der einen und dem Glauben der Täuflinge auf der anderen Seite" (Barth, 1967:204). Hier is Barth inderdaad by die kern van die probleem.

Tereg verwerp Karl Barth alle vorme van 'kindergeloof' of 'fides aliena'. Die 'fides infantilis' soos Luther dit byvoorbeeld nog sterk gepropageer het, was vir Barth volstrek onaanvaarbaar.

Wel benadruk Barth geheel tereg dat daar 'n verband is tussen doop en geloof. Hy verwyt Calvyn wat 'n verband lê tussen die doop en die later, bewuste geloof van die dopeling, dat die groot hervormer op daardie manier die doop in twee dele opdeel.

Dit is nogal opvallend dat Barth sy polemiese geskrif oor die doop op ' $n$ gemoedelike trant beëindig. Genoeg skrywe hy, genoeg "über diese kümmervolle Sache... Sie ist eine tief unordentliche Taufpraxis", maar die kerk het ook aan sy "kümmerlichen Predigt und an so vielen andern Kümmerlichkeiten" nie te gronde gegaan nie (Barth, $1967: 213,214$ ).

Ten slotte roep hy kerkleiers en teoloë sowel sinodales as pres 
biteriane en episkopales op om hulle oor die kinderdoop te besin. Barth het self met sy kritiek op die kinderdoop 'n kragtige impuls tot hernude besinning oor die kinderdoop gegee.

In hierdie verband is die opmerking van G. Oorthuys van groot betekenis. Hy skrywe dat dit God behaag het "door een man, naar wie men wel luisteren moet, de kinderdoop te laten aanvechten, opdat de gemeente van Christus dit klaarste bewijs van Gods vrije, aan geen enkele menselijke prestatie gebonden genade, op de ware prijs zou stellen en er mede woekeren" (Oorthuys, 1948: 63).

\section{Kritiese evaluering}

Wanneer ons Barth se argumente teen die kinderdoop krities gaan weeg, dan moet daar eers gekyk word na sy historiese argument teen die kinderdoop. Karl Barth verbind die kinderdoop baie sterk aan die corpus Christianum. Volgens Berkouwer is die verband tussen kinderdoop en corpus Christianum "automatisch en schier vanzelfsprekend" (Berkouwer, 1947:46). Dit bly egter 'n oop vraag of die verband so vanselfsprekend is as wat Barth wil voorgee.

Bremmer toon met tal van historiese gegewens aan dat die kinderdoop reeds in die vroeë kerk ver voor Konstantyn al bestaande praktyk was. Hoe kan Tertullianus in die geskrif De Baptismo wat hy kort na $200 \mathrm{n}$.Chr. geskryf het reeds teen die praktyk van kinders te doop protesteer as hierdie praktyk eers later tot stand gekom het? (Bremmer, 1983:505). Die kerkorde van Hippolitus, omstreeks $215 \mathrm{na} \mathrm{Chr}$., het 'n duidelike bepaling dat kindertjies wat deur die sonde besoedel is, gedoop moet word.

Origenes skryf kort na 231 na Chr. dat die gewoonte om kinders te doop dateer "ab apostolis", vanaf die apostels. Ook grafskrifte uit die tyd van die katakombes wys op die doop van kinders (vgl. in al hierdie gegewens Wolinski, 1971, passim).

Dit bly by Barth onverklaarbaar dat hy waar hy elders in sy werke so sterk die verbond beklemtoon, hy in sy doopleer en met name in sy kritiek op die kinderdoop die verbond prakties nie ter sprake bring nie (vgl. König, 1971:123). In sy kritiek op Barth se doopleer het G. C. Berkouwer die vinger op die seerplek gelê (1947: 9C).

Barth se kritiek op die kinderdoop hou verband met sy siening op die skepping. Barth sien dit wat met die skepping gegee is, as 'n bedreiging vir die soewereiniteit van die genade. Hiermee hang ook ten nouste Barth se benadering van die verhouding tussen die Ou Testament en die Nuwe Testament saam. Hy stel die Ou Testament as 'n natuurlike verbond teenoor die Nuwe Testament as 'n geestelike verbond. Die besnydenis het, aldus Barth, te doen met die natuurlike geboorte (Barth, $1943: 31$ ).

Eintlik is daar geen prinsipiële verskil tussen die kritiek van Karl Barth en die kritiek van die Doperse beweging op die kinderdoop nie (Berkouwer, 1947:97, 134). Die verskil is alleen dat Barth by verwerping van die kinderdoop tog nie vir 'n herdoop, 'n weerdoop pleit nie. Hier is Barth meer op een lyn met Tertullianus. Barth is beslis nie ' $n$ anabaptis nie. 
Berkouwer het in sy kritiek op Barth duidelik aangetoon dat die Ou Testament nie ' $n$ minder geestelike verbond is as die Nuwc Testament nie asof die Nuwe Testament geesteliker sou wees in die sin dat alleen deur ' $n$ individuele geloofsbeslissing geëis word om tot die verbond toe te tree (Berkouwer, 1947:90,96).

In sy studie oor die sakramente wys Berkouwer daarop dat met betrekking tot die verhouding Ou Testament en Nuwe Testament, "natuurlik" nie teenoor "geestelik" staan nie, maar ongeloof teenoor geloof as korrelaat van die belofte van God (Berkouwer, $1954: 221$ ).

Die verhouding tussen die Ou Testament en die Nuwe Testament en die regte siening op die verbond is bepalend vir die aanvaarding van die kinderdoop. Calvyn het die handhawing van die kinderdoop gefundeer in die substansiële eenheid tussen Ou Testament en Nuwe Testament (Institusie II, 10, 11; Komm. op Gal 4:1 2). Terwyl die Doperse Beweging die verhouding van Ou en Nuwe Testament aan. dui as stoflik teenoor geestelik, kom Calvyn met die fyn onderskeiding van jeug teenoor manlike rypheid en volwassenheid. Hy spreek van die kinderlike staat van die kerk in die Ou Testament (status pueritiae esslesiae) terwyl in die Nuwe Testament hierdie kinderlike staat van die kerk uitgroei tot volwassenheid (Komm. op Gal $4: 1.2)$.

Die verbond wat God met Abraham opgerig het, is ook met sy saad opgerig en dan nie alleen saad in biologiese sin te verstaan nie. Woelderink het daarop gewys dat God terstond sy verbond uitgebrei het tot hulle wat met geld gekoop is en dus nie biologies Abraham se saad was nie (Gen 17:12). Die gemeente van God in Abraham se huis was dus nie op bloed- of biologiese afstamming gegrond nie maar op God se genadige verkiesing en verbond (Woelderink, 1948: 49).

Die kern van Calvyn se verdediging van die kinderdoop lê in die verband wat daar in die Bybel is tussen besnydenis en doop. Dit het Karl Barth goed raakgesien. Calvyn se Skrifbewys vir die een heid van besnydenis en doop vind hy in Rom 4:11 waar die besnydenis 'n seël van die geregtigheid van die geloof genoem word.

As nou die besnydenis as teken en seël van geloofsgeregtigheid nie net aan gelowiges bedien word nie maar ook aan gelowiges sc kinders, dan is dit te verwagte dat die Nuwe-Testamentiese seël van die geloofsgeregtigheid ook aan kinders van gelowiges bedien moet word (vgl. König, $1971: 129$; Floor, $1983: 18-21$ ).

Die verhouding doop-geloof is van die allergrootste belang. Dit kom ook telkens na vore in die gesprek oor die doop. Hoewel die eenheid van geloof en doop onlosmaaklik is, beteken dit hoegenaamd nie dat die geloof altyd aan die doop moet voorafgaan nie.

Volgens Rom $4: 11,12$ is daar 'n dubbele moontlikheid. Op grond van Mark 16:16 word deur die teenstanders van die kinderdoop geredeneer dat die geloof chronologies aan die doop behoort vooraf te gaan (König, $1986: 202$ ).

Die volwassebesnydenis as teken en scël van die geregtigheid van die geloof gaan oor in 'n kinderbesnydenis. Ook aan die kindertjies word deur die sakrament van die besnydenis die waarborg gc- 
gee dat hulle deur geloof gered word. Hierdie waarborg ontvang hulle nie omdat hulle reeds glo nie. God gee die waarborg aan hulle wat nog glad nie glo of selfs kan glo nie. Wel roep hierdie besnydenis die kindertjies tot geloof op. Die harte van die kindertjies moet besny word.

Nou is die doop in die Nuwe Testament soos die besnydenis in die Ou Testament op die heilsgebeure in Christus betrek. Dit is gelowiges wat in die Nuwe Testament ged oop word. Maar ook by hulle kinders wat gedoop word, bly die verhouding: geloof-doop van $\mathrm{krag}$. Alleen by hulle gaan die doop aan die geloof vooraf (Floor, 1983 22-24).

Daar moet met klem op gewys word dat die natuurlike faktor van bloedafstamming ook reeds in die Ou Testament nie as basis vir die besnydenis gedien het nie. Ons mag die besnydenis in die Ou Testament nie tot 'n suiwer vleeslike saak van bloed, voortplanting en nasionale afkoms beperk nie. Dit is die groot fout van Karl Barth dat hy die besnydenis net tot die natuurlike geboorte beperk.

Daar is wel ' $n$ biologiese motief met betrekking tot die besny. denis, maar daardie motief is nie deurslaggewend nie. Die natuurlike gebeure van voortplanting, wat 'n skeppingsopdrag van God is, word in God se verbond nie onderbreek of verontagsaam nie maar in berekening gebring: vir jou en jou nageslag geld die verbond (Heyns, $1978: 342$ ).

\section{Die agtergrond van Barth se kritiek op die kinderdoop}

Dit is nie so eenvoudig om die diepste motiewe van Barth se verset teen die kinderdoop bloot te le nie. Wie kennis neem van Barth se teologie en wie dan tot die ontdekking kom dat die verbond sterk in Barth se dogmatiek figureer, nie soseer as term nie maar wel as motief (Van Ruler, 1945:75), kry die indruk dat Barth se verset teen die kinderdoop ' $n$ Fremdkörper in sy teologie is.

G. C. Berkouwer het ' $n$ indringende ondersoek ingestel na die agtergrond van Barth se kritiek op die kinderdoop. Hy is oortuig dat daar ' $n$ samehang is tussen Barth se kritiek op die kinderdoop en sy siening op die verhouding tussen skepping en verlossing (Berkouwer, 1947:133). In wese is daar volgens Berkouwer nie verskil tussen Barth se bestryding van die kinderdoop en die kri tiek van die Anabaptiste nie (Berkouwer, 1947:134). Daar is 'n duidelike Doperse trek in Barth se denke. Die teenstelling sondegenade word oorheers deur die teenstelling natuur-genade.

Kurt Aland sien in Barth se doopleer 'n te optimistiese mensbeskouing. Barth heg aan "das Handeln der Menschen, die zur Taufe kommen" 'n te groot waarde. Dit skep volgens Aland die indruk dat Barth en sy volgelinge in die verwerping van die kinderdoop self na 1933 waarin allerlei verskriklike dinge deur mense gedoen is, nie kennis geneem het van Luther se geskrif De servo artitrio nie (Aland, 1971:58). Bremmerr maak hierby die opmerking: "Zou daar dan ook niet één van de redenen liggen waarom de kinderdoop er bij Barth zo slecht afkomt" (Brummer, 1983:512)?

Met sy bekende radikalisme was dit Barth se bedoeling om die 
leer van die doop te suiwer van elke relasie met die natuurlik-ge gegewene. Een van sy eie leerlinge het in verband hiermee die vraag gevra of Barth in sy afwysing van die kinderdoop "hier niet ten offer valt aan een door de kerk toch altijd verworpen spiritualisme", (Van Niftrik, 1940:200).

Barth het in sy teologie voortdurend die geweldige kwalitatiewe verskil tussen Skepper en skepsel beklemtoon. God is God; Hy is die gans Andere, die Soewereine, wat in sy vryheid en almag radikaal bo die wêreld troon en wat Hom in vryheid deur sy Woord open baar - waar Hy wil en wanneer Hy wil.

Vanuit hierdie fundamentele konsepsie waarsku Barth skerp teen alles wat in die skepping as konstitutief vir die genade beskou kan word. Die Reformatore het in hul bestryding van die Rooms-Katolieke denke die Roomse teenstelling: natuur-genade onder skoot geneem. So het Karl Barth die stryd aangebind teen die natuurlike teologie met sy skeppingsordeninge en as gevolg daarvan 'n positiewe waardering van bloed ras, bodem en volk.

Maar die Reformatore het in hulle stryd teen die Roomse konsepsie van natuur en genade en die kompromis tussen die natuurlike en die bonatuurlike tog nie in die slaggat van die Anabaptiste geval nie. Die Wederdopers het op die ou end 'n breuk tussen skepping en herskepping geforseer. Dit het gelei tot hulle radikale bestryding van die kinderdoop, omdat hulle daarin ' $n$ vermenging van natuur en genade, van natuurlik en geestelik gesien het.

Karl Barth het in sy stryd teen elke vorm van natuurlike teologie ook die kinderdoop aangeval, omdat hy in die kinderdoop 'n naturalisering van die verbond gesien het, omdat die natuurlike afstamming 'n "prae" sou wees vir die ingang in die Koninkryk van God.

Die Reformatore het uit reaksie teen Rome se natuur- bo-natuur skema nie die Anabaptistiese teenstelling natuur genade oorgeneem nie. Hulle het nie verval in 'n veragting van die natuur nie, maar die klem laat val op die teenstelling sonde-genade.

Hulle belydenis van die totale verdorwenheirl van die menslike natuur het hulle nie gebring tot veragting van die natuur as sodanig nie.

Prinsipieel is Karl Barth op hierdie punt meer in die lyn van die Anabaptiste as van die Reformatore. Sy verwerping van die kinderdoop kan dan ook logies uit sy skeppingsleer verklaar word.

By alle erns wat eie is aan die Anabaptiste kan nie ontken word dat daar by hulle ' $n$ oppervlakkige sondebeskouing te bespeur is nie.

Dit lyk of ons by Barth dieselfde sien en daarom is Kurt Aland se opmerking oor Barth se optimistiese mensbeskouing as agtergrond van sy kritiek op die kinderdoop nie geheel onvanpas nie.

Berkouwer het die belangrike stelling gemaak: "De geschiedenis van kerk en theologie is daar om te bewijzen, dat bij het in een bepaalde vorm aan de orde stellen van de tegenstelling natuur-genade altijd beslissingen vallen van vér-strekkende gevolgen voor de kerk en daarom voor de wereld" (1947: 135).

Ons vind in Barth se teologie met sy eensydige beklemtoning 
van die Evangelie 'n onderbeklemtoning van die skepping en die wet. Dit is opvallend dat ons in Barth se Kirchliche Dogmatik nie 'n leer van die skepping as 'n verklaring van die eerste artikel van die Apostoliese Geloofsbelydenis aantref nie. Die skepping is vir Barth nie die goddelike apriori, die synsgrond waar in die tweede artikel van die Credo van uitgegaan word nie. In wese gaan by Barth die verlossing aan die skepping vooraf. Die betreffende hoofstuk in sy Kirchliche Dogmatik dra dan ook die titel Schöpfung und Bund.

By Barth vind ons dan ook nie 'n prinsipiële erkenning van skeppingstrukture nie (Aalders, 1984:31). Dit behoef ons dan ook nie te verwonder dat daar in Barth se denke geen plek vir die kinderdoop is nie.

\section{Bibliografie}

Aalders, W., den Boer, C., de Reuver, A. 1984. Barth-Kohlbrugge-Miskotte: Ontwikkeling of breuk? Kampen.

Aland, K. 1971. Taufe und Kindertaufe, Gutersloh.

Barth, K. 1919. Der Römerbrief, Bern.

Barth, K, 1943. Die kirchliche Lehre von der Taufe.

Barth, K. 1967. Kirchliche Dogmatik, IV, 4, Zürich.

Barth, K. 1951. Die Taufe ein Sakrament.

Berkouwer, G. C. 1947. Karl Barth en de kinderdoop, Kampen.

Berkouwer, G. C. 1954. Dogmatische Studiën - De Sacramenten, Kampen.

Bremmer, R. H. 1983. Karl Barth en de kinderdoop (in: Van't Spijker, W. (red), Kandom de doopvont, Goudriaan).

Dekker, A. Puchinger, G. 1969. De oude Barth, Kampen.

Floor. L. 1984. De doop met de Heilige Geest, Kampen.

Floor, L. 19831. Die Heilige Doop in die Nuwe Testament. Potchefstroom.

Floor, $L$. 1984. Die verhouding van Ou en Nuwe Testament, in: In die Skriflig, Jaarg. 18, Nr. 69. Maart.

Floor, L. 1983\%. Die verhouding doop en geloof, in: In die Skriflig, Jaarg 17 Nr. 67, Sept. 1983.

Heyns J. A. 1978. Dogmatiek, Pretoria.

Jonker, W. D. 1981. Die Gees van Christus. Pretoria.

König, A. 1971. Karl Barth se finale verwerping van die kinderdoop, in: Theologia Evangelica, Jaarg. IV, Nr. 1 en 2, Maart en Junie.

Kömig, A. 1986. Die doop as kinderdoop en grootdoop, Pretoria.

Oorthuys, W. 1948. De sacramenten, Nijkerk.

Van Niftrik, G. C. 1940. Sola fide. De rechtvaardigingsleer in de Nieuwere theologie, Nijkerk.

Versteeg, J. P. 1983. De doop volgens het Nieuwe Testament (in: Van't Spijker, W. (red), Rondom de doopvont, Goudriaan).

Woelderink, J. G. 1948. Bespreking van Berkouwers boek: De Sacramenten, in: Enigheid des geloofs, 2de Jaarg.

Wolinski, W. 1971. Diskussion um die Taufe, Munchen. 